\title{
Analisis Tekno Ekonomi terhadap Pemilihan Teknologi Fixed Wireless Access (FWA) untuk Penyelenggaraan Layanan Telepon Tetap Di Indonesia
}

\author{
Dr. Muhammad Imam Nashiruddin, ST,MT \\ Dosen Manajemen Informatika \\ Politeknik LP3I Bandung \\ Email : imam.nashiruddin@gmail.com
}

\begin{abstract}
Abstrak : Fixed Wireless Access (FWA) saat ini menjadi pilihan utama bagi operator telepon tetap di Indonesia untuk menggelar jaringan akses secara cepat dengan investasi yang relatif efisien. Meskipun berbagai macam teknologi FWA telah tersedia di pasaran, pemilihan teknologi FWA yang tepat menjadi persoalan mendasar bagi penyedia layanan telepon tetap, terutama operator baru, agar memiliki daya saing yang baik menghadapi operator eksisting (incumbent operator).
\end{abstract}

Oleh karena itu, dalam penelitian ini dilakukan evaluasi yang komprehensif dalam memilih teknologi FWA yang paling tepat untuk penyelenggaraan layanan telepon tetap di Indonesia. Adapun metoda yang digunakan adalah studi komparatif antara teknologi FWA berbasis CDMA2000-1X dan GSM1800 dengan menggunakan kriteria evaluasi secara teknis, ekonomis serta kelayakan usahanya di Indonesia. Kedua teknologi tersebut dipilih sebagai studi kasus karena paling banyak digunakan di Indonesia dan memperoleh respon yang relatif baik dari pengguna dan penyedia layanan.

Hasil penelitian menunjukkan bahwa teknologi FWA berbasis CDMA2000-1X layak dipilih karena lebih unggul secara teknis maupun ekonomis dibandingkan dengan GSM1800. Hasil analisa kelayakan usaha juga memperlihatkan bahwa penyelenggaraan layanan telepon tetap di Indonesia menggunakan FWA berbasis CDMA2000-1X akan menghasilkan kelayakan bisnis yang paling baik dengan ambang batas jumlah pertambahan pelanggan per tahun dan pendapatan rata-rata per pelanggan yang paling rendah untuk mencapai kelayakan usaha.

Keywords : ICT Management, Fixed Wireless Access (FWA), GSM18000, CDMA2000-1X

\section{Pendahuluan}

\subsection{Latar Belakang}

Bisnis telekomunikasi di Indonesia telah mengalami perubahan besar sejak diberlakukan Undang - Undang No. 36 Tahun 1999 tentang Telekomunikasi. Akibatnya, bisnis telekomunikasi domestik yang semula dimonopoli PT. TELKOM dan bisnis telekomunikasi internasional yang dikuasai oleh PT. INDOSAT dan PT. SATELINDO menjadi terbuka untuk operator lain secara 
berkompetisi. Kebijakan kompetisi telekomunikasi domestik yang semula direncanakan akan dimulai pada tahun 2010, namun dipercepat menjadi tahun 2002 karena terdorong oleh kebutuhan peningkatan densitas telepon yang terus mendesak untuk mendukung pemulihan ekonomi nasional.

Dalam membangun jaringan akses tetap lokal, para operator umumnya cenderung menggunakan teknologi berbasis Fixed Wireless Access (FWA). Teknologi ini dipilih karena selain cepat dalam pembangunannya, investasi yang diperlukan juga relatif lebih efisien dibandingkan dengan teknologi akses jaringan kabel.

Untuk mengelar jaringan akses berbasis FWA, operator dapat menggunakan berbagai teknologi FWA yang ada di pasaran, seperti selular, cordless, teknologi proprietary dan microwave. Masing-masing teknologi tersebut memiliki karakteristik dan konfigurasi teknis serta nilai ekonomis yang relatif berbeda sehingga harus disesuaikan dengan kebutuhan, prospek pasar, regulasi dan kondisi lingkungan di wilayah yang akan dibangun.

Karena itu, diperlukan pemilihan teknologi FWA yang tepat agar operator telepon tetap dapat menggelar jaringan dan menyelenggarakan layanan secara cepat dengan investasi yang relatif efisien, namun mampu memenuhi kebutuhan saat ini (voice) dan mengakomodasi layanan yang diperkirakan akan berkembang pesat di masa depan (internet dan multimedia). Bagi operator baru, pemilihan teknologi FWA yang tepat juga dapat meningkatkan daya saing menghadapi operator eksisiting.

Sehubungan dengan hal tersebut, dalam penelitian ini dilakukan analisa aspek teknis, ekonomis serta kelayakan usaha terhadap penyelenggaraan layanan telepon tetap di Indonesia dengan menggunakan studi kasus perbandingan teknologi FWA yang paling banyak digunakan dan memungkinkan untuk diimplementasikan di Indonesia, yaitu GSM1800 dan CDMA 2000-1X.

\subsection{Tujuan Penelitian}

Penelitian ini bertujuan untuk mengevaluasi dan mengkaji pemilihan teknologi Fixed Wireless Access (FWA) untuk penyelenggaraan layanan telepon tetap di Indonesia.

\subsection{Manfaat Penelitian}

Hasil evaluasi dan kajian teknis, ekonomis maupun kelayakan usaha dalam penelitian ini diharapkan bisa memberikan kontribusi dalam pemilihan teknologi FWA yang paling tepat untuk di implementasikan di Indonesia.

\subsection{Identifikasi Permasalahan}

Agar dapat dilakukan pemilihan teknologi FWA yang tepat dalam penyelenggaraan layanan telepon tetap di Indonesia perlu didukung analisa untuk menggambarkan keunggulan masing-masing alternatif teknologi, yaitu : 


\section{Analisa kriteria teknis, meliputi :}

a. topologi jaringan,

b. kualitas layanan suara,

c. kapasitas pelanggan,

d. kebutuhan BTS,

e. cakupan BTS,

f. performansi terhadap lingkungan radio,

g. perencanaan \& pengembangan cakupan,

h. ketersediaan alokasi frekuensi,

i. kemampuan multilayanan,

j. akomodasi layanan masa depan,

k. kemudahan migrasi 3G, serta

1. dukungan konvergensi jaringan.

\section{Analisa kriteria ekonomis, meliputi :}
a. biaya implementasi,
b. investasi per pelanggan, serta
c. pengaruh kepadatan trafik pelanggan terhadap investasi.

3. Analisa kelayakan usaha dan sensitifitas, untuk menggambarkan prospek penyelenggaraan layanan telepon tetap di Indonesia, sekaligus mengetahui dampak implementasi teknologi yang digunakan terhadap kelayakan usahanya.

\subsection{Batasan Masalah}

Pembahasan dalam penelitian ini dibatasi dengan asumsi dan permasalahan sebagai berikut :

1. teknologi FWA yang dibandingkan adalah GSM1800 dan CDMA2000-1X.

2. analisa teknis dan ekonomis dilakukan terbatas pada kriteria yang telah ditetapkan sebagaimana dalam butir 1.4.a. ,

3. analisa kelayakan usaha yang dilakukan terbatas pada proyeksi bisnis menggunakan asumsi base case,

4. indikator kelayakan usaha yang di analisa adalah Net Present Value (NPV), Internal Rate Return (IRR), Payback Period (PP) dan Profitability Index (PI),

5. analisa ekonomis dan kelayakan usaha, menggunakan 3 asumsi penyelenggaraan, yaitu CDMA2000-1X, GSM1800 dan Network Sharing GSM1800, dan

6. analisa sensitifitas yang dilakukan menggunakan 4 skenario bisnis, yaitu skenario base case, ambang, optimis dan pesimis terhadap jumlah pelanggan baru per tahun dan ARPU masing-masing layanan.

\subsection{Metodologi Penelitian}

Metode penelitian yang digunakan adalah studi komparatif berdasarkan beberapa literatur dan data penunjang dari operator telepon tetap, regulasi pemerintah, hasil riset/survey dan sumber lain yang terpercaya. 
Metode penelitian yang dilakukan menggunakan langkah-langkah sebagai berikut:

1. Melakukan analisa kemampuan teknis dari teknologi FWA yang dipilih dengan menggunakan kriteria teknis yang telah ditentukan,

2. Melakukan analisa aspek ekonomis sesuai kriteria butir 1.4.b untuk menunjang analisa teknis yang telah dilakukan,

3. Melakukan analisa kelayakan usaha untuk menggambarkan prospek penyelenggaraan layanan telepon tetap menggunakan teknologi FWA di Indonesia,

4. Melakukan analisa sensitifitas terhadap jumlah pelanggan dan pendapatan rata-rata yang dihasilkan oleh pelanggan untuk mendapatkan ambang batas agar kelayakan usaha dapat dicapai, dan

5. Merangkum seluruh hasil analisa sehingga dapat menggambarkan keunggulan masing-masing teknologi FWA sebagai pertimbangan dalam memberikan rekomendasi pemilihan teknologi FWA yang sebaiknya di implementasikan.

\section{Teknologi Fixed Wireless Access (FWA)}

\subsection{Konfigurasi Umum Jaringan Akses}

Jaringan akses (access network) merupakan media telekomunikasi yang menghubungkan terminal sisi pelanggan (customer premises equipment) dengan jaringan telekomunikasi inti (core network). Media jaringan akses dapat berupa kabel tembaga, kabel koaksial, serat optik dan radio (mobile wireless ataupun fixed wireless access).

Pada implementasinya, jaringan akses dapat menggunakan salah satu atau gabungan dari media transmisi tersebut dengan menggunakan titik distribusi atau konsentrator, seperti diperlihatkan dalam Gambar 1 dibawah ini.

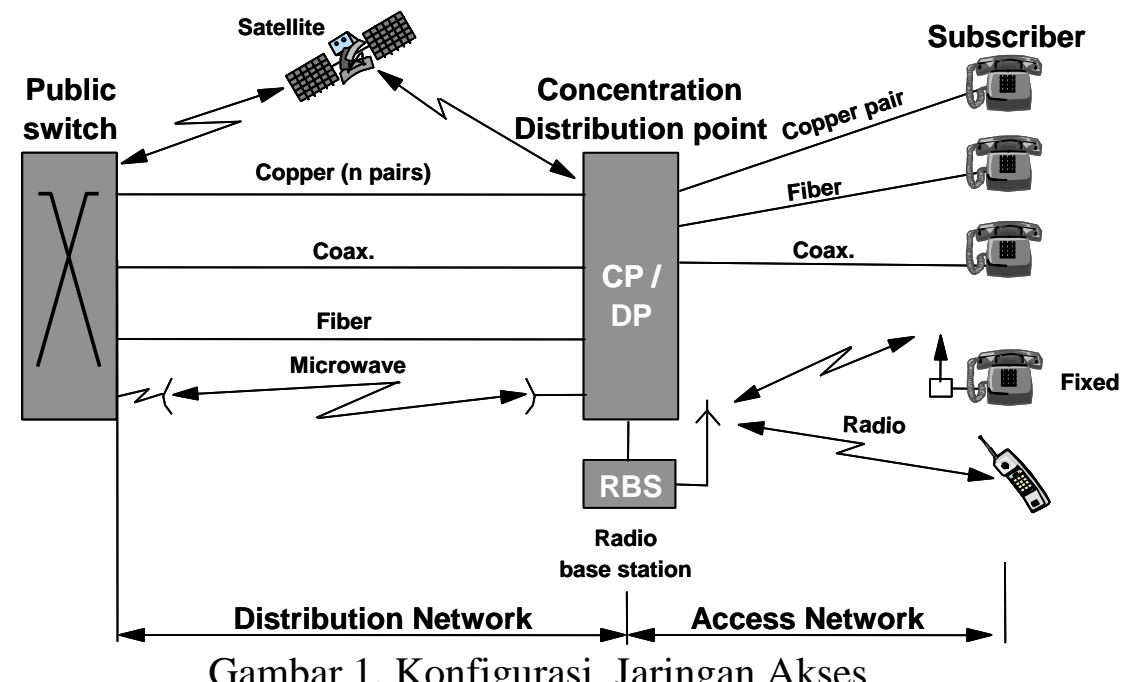

Gambar 1. Konfigurasi Jaringan Akses

\subsection{Perbandingan Akses Wireless dan Wireline}

Dibandingkan dengan teknologi akses melalui kabel yang memerlukan pembuatan pipa duct atau tiang telepon, maka teknologi radio, tidak diragukan lagi, jelas 
lebih mudah dan lebih murah untuk diinstalasi. Bagi kebanyakan operator telepon tetap, kelebihan utama wireless access antara lain:

1. adanya peran konsentrasi BTS (base transceiver station) sehingga untuk jumlah pelanggan yang sama memerlukan infrastruktur yang lebih sedikit,

2. memiliki fleksibilitas yang secara otomatis menyesuaikan jumlah sirkit radio dengan kebutuhan trafik,

3. keinginan operator untuk tidak merencanakan dulu dari awal, dimana dan untuk siapa (residensial atau bisnis) yang akan menjadi pelanggannya sehingga tidak memerlukan persiapan instalasi infrastruktur pendukungnya (kabel, duct, tiang telepon, dll) yang bisa jadi tidak akan pernah digunakan,

4. memungkinkan operator untuk menyediakan koneksi yang cepat ke berbagai lokasi pelanggan potensial yang terletak dalam cakupan BTS,

5. pada beberapa kasus, memungkinkan end user untuk mendapatkan dan meng-instalasi sendiri perangkat terminal miliknya,

6. memungkinkan end user untuk menghubungkan dan menggunakan terminal pelanggan yang sama (telepon, facsimile, answering machine, modem, dll) seperti halnya pada jaringan kabel biasa, dan

7. dapat menjangkau daerah yang sulit dijangkau oleh jaringan kabel.

Namun demikian, terdapat pula beberapa kelemahan pada jaringan akses nirkabel, diantaranya :

1. dibatasi ketersediaan spektrum frekuensi,

2. keterbatasan bandwith per pelanggan,

3. adanya kemungkinan gangguan propagasi radio,

4. dimungkinkan terjadi bloking disisi akses, serta

5. memerlukan catuan listrik pada perangkat pelanggan.

\subsection{Implementasi Teknologi FWA}

Ditinjau dari standar/basis teknologi yang digunakan, implementasi teknologi Fixed Wireless Acces (FWA) dapat dikelompokkan kedalam 4 kategori utama :

1. teknologi FWA yang menggunakan standar teknologi radio selular,

2. teknologi FWA yang menggunakan standar teknologi cordless,

3. teknologi FWA yang menggunakan teknologi proprietary, dan

4. teknologi FWA yang menggunakan basis teknologi microwave.

\subsubsection{FWA berbasis Teknologi Cellular}

Dari semua aplikasi komunikasi wireless, telepon selular mengalami pertumbuhan paling cepat. Teknologi selular terkini yang sedang berkembang di dunia dan menjadi pertimbangan utama para operator telepon saat ini adalah GSM dan CDMA2000-1X. Dengan menggunakan FWA berbasis teknologi selular diharapkan dapat dicapai investasi yang lebih efisien, lebih cepat dan mampu melakukan konvergensi dengan standar yang luas digunakan diseluruh dunia. 


\subsubsection{Fixed Wireless GSM}

GSM (Global System for Mobile Communication) merupakan teknologi selular generasi kedua (digital) yang dikembangkan oleh ETSI (http://www.etsi.org) di Eropa sejak tahun 1991 pada frekuensi $800 \mathrm{Mhz}$ dan $1800 \mathrm{MHz}$. Standar ini telah digunakan secara luas dan sekitar $95 \%$ pelanggan selular di dunia menggunakan standar ini. Arsitektur FWA yang menggunakan teknologi GSM diperlihatkan dalam Gambar 2. berikut ini.

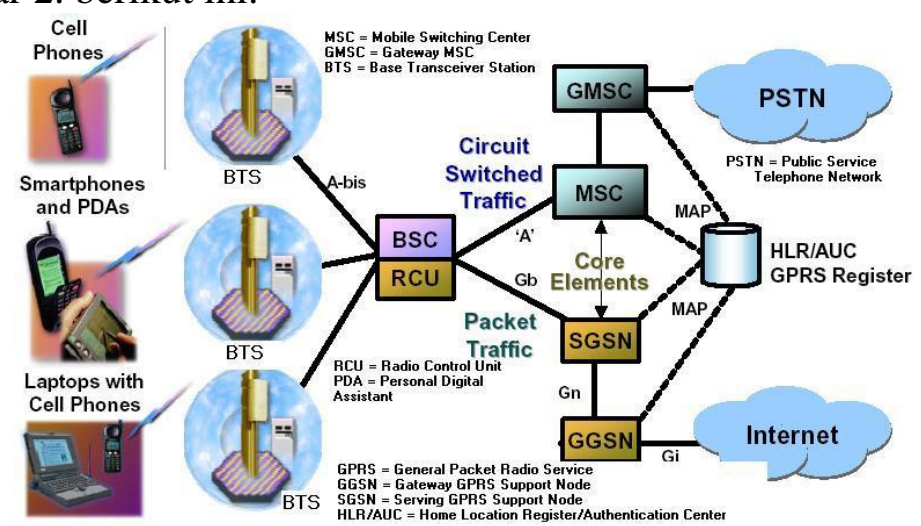

Gambar 2. Arsitektur FWA berbasis GSM

\subsubsection{Fix Wireless CDMA 2000-1X}

CDMA 2000-1X merupakan teknologi selular digital generasi ketiga (3G) yang dikembangkan oleh 3GPP2 (http://www.3gpp2.org). Standar ini telah mulai dipakai secara luas di Korea, Jepang, China, USA dan Brazil. Arsitektur FWA yang menggunakan teknologi ini diperlihatkan dalam Gambar 3.

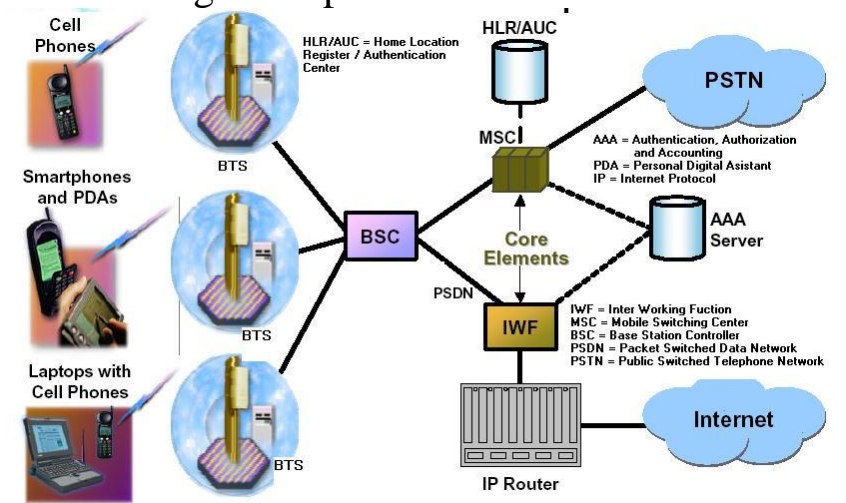

Gambar 3. Arsitektur FWA berbasis CDMA 2000-1X

\subsubsection{FWA berbasis Teknologi Proprietary}

FWA berbasis teknologi proprietary didesain khusus untuk implementasi fixed wireless access dan menggunakan baik teknologi TDMA maupun CDMA. Berbeda dengan FWA yang berbasis teknologi selular, FWA berbasis teknologi proprietary tidak memerlukan fungsi switching tersendiri. Kelemahan utama sistem ini adalah teknologi yang vendor proprietary sehingga biasanya tidak kompatibel dengan vendor lainnya. 
Teknologi FWA proprietary yang cukup menjanjikan dan mulai diterima pasar adalah yang berbasis teknologi CDMA. Sampai saat ini, terdapat 3 vendor utama CDMA FWA proprietary yang berkompetisi di dunia, yaitu L3 Communication, Lucent Airloop dan Airspan. Contoh arsitektur FWA yang berbasis teknologi proprietary diperlihatkan dalam Gambar 4.

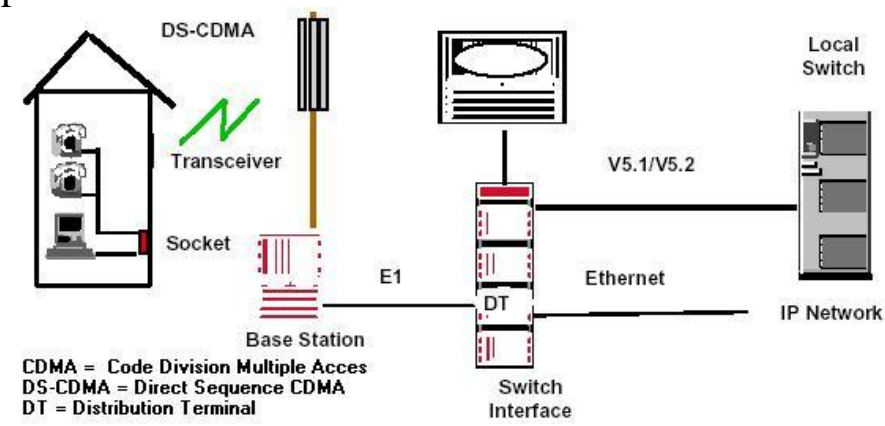

Gambar 4. FWA berbasis Teknologi Proprietary

\subsubsection{FWA berbasis Teknologi Cordless}

Teknologi cordless didesain menggantikan jaringan kabel telepon untuk memberikan solusi terhadap trafik dengan kapasitas tinggi, namun dengan kompleksitas yang rendah. Sistem ini cukup sukses diimplementasikan dalam aplikasi FWA. Diantara teknologi cordless lainnya, DECT merupakan yang paling sesuai dengan persyaratan FWA, karena selain mengutamakan aspek layanan, kondisi operasional, efisiensi spektrum dan regulasi, DECT juga memiliki kemampuan untuk terhubung dengan jaringan tetap PSTN atau bergerak dan diyakini mampu berevolusi dengan jaringan wireless generasi ketiga (3G). Arsitektur FWA berbasis teknologi cordless DECT diperlihatkan dalam Gambar 5 berikut.

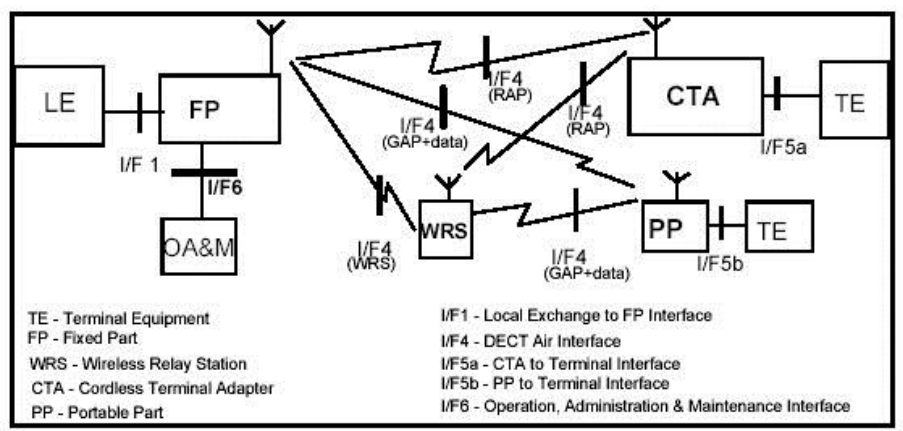

Gambar 5. FWA berbasis Teknologi Cordless

\subsubsection{FWA berbasis Teknologi Microwave}

Teknologi FWA berbasis teknologi microwave atau biasa dikenal juga dengan point to multipoint (PMP) ini didesain untuk memberikan layanan pita lebar (broadband) pada saluran wireless sehingga aplikasinya lebih banyak untuk 
transmisi data multimedia. Dibanding dengan teknologi FWA lainnya, sistem ini kurang baik efisiensi spektrumnya.

Meskipun demikian, sistem ini tetap mampu memenuhi persyaratan FWA bila didesain khusus untuk menggantikan jaringan kabel, terutama di daerah rural karena memiliki jarak jangkau hingga $30 \mathrm{~km}$. Diantara teknologi yang menggunakan sistem ini adalah PMP TDMA, MMDS dan LMDS. Contoh arsitektur teknologi FWA berbasis teknologi microwave diperlihatkan dalam Gambar 6.

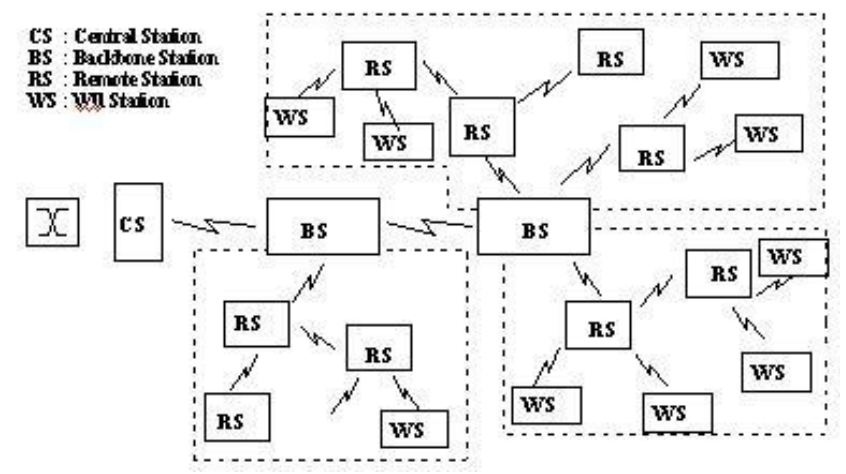

Gambar 6. Teknologi FWA berbasis Teknologi Microwave

\subsection{Perbandingan Teknologi FWA}

Secara keseluruhan, perbandingan berbagai macam model teknologi FWA diatas, dirangkum dalam Tabel 1 dibawah ini.

Tabel 1. Perbandingan Teknologi FWA

\begin{tabular}{|l|l|l|l|l|}
\hline \multirow{2}{*}{ Perbandingan } & \multicolumn{2}{c|}{ Selular } & \multicolumn{1}{c|}{ Propietary } & \multicolumn{1}{c|}{ Cordless } \\
\cline { 2 - 4 } & \multicolumn{1}{c|}{ Microwave } \\
\hline Layanan Telepon & Baik & Baik & Baik & Lebih optimal untuk Data \\
\hline Data & $14-384 \mathrm{Kbps}(3 \mathrm{G})$ & $144 \mathrm{Kbps}$ & $500 \mathrm{Kbps}$ & $10 \mathrm{Mbps}$ \\
\hline & $2 \mathrm{Mbps}(3 \mathrm{G})$ & & & \\
\hline Pita Frekuensi & $800 / 900 \mathrm{MHz}$ & $1,7-2 \mathrm{GHz}$ & \\
& $1800 / 1900 \mathrm{Ghz}$ & $1,5-4 \mathrm{GHz}$ & & \\
\hline Line of Sight (LOS) & Relatif tidak terpengaruh & Relatif berpengaruh & Relatif berpengaruh & Sangat berpengaruh \\
\hline Layanan Tambahan & Baik & Baik & Terbatas & Sangat terbatas \\
\hline Kapasitas & Tinggi & Tinggi & Sangat Tinggi & Sangat Tinggi untuk Data \\
\hline Jarak Jangkauan & Tinggi (Hingga 35 Km) & Rendah $(6-15 \mathrm{~km})$ & Sangat Rendah $(5 \mathrm{~km})$ & Tinggi (30 Km) \\
\hline Implementasi & Sangat Luas & Terbatas & Terbatas, tetapi bertumbuh & Sangat terbatas, terutama di negara maju \\
\hline Biaya Implementasi & Moderat & Mahal & Relatif Mahal & Sangat Mahal \\
\hline
\end{tabular}

Dari tabel diatas dapat diketahui bahwa teknologi FWA berbasis selular memiliki keunggulan dibanding dengan basis teknologi lainnya, antara lain memiliki kualitas yang baik untuk layanan teleponi, kecepatan data yang relatif tinggi, toleransi yang tinggi terhadap line of sight, layanan tambahan yang cukup baik, kapasitas yang tinggi, radius jangkauan yang cukup jauh, telah dipakai secara luas dan biaya implementasi yang cukup moderat.

\section{Penyelenggaraan Layanan Telepon Tetap di Indonesia}

\subsection{Peran Strategis terhadap Pertumbuhan Ekonomi}

Industri telekomunikasi menjadi perhatian banyak peneliti karena kenyataan menunjukkan bahwa teknologi informasi dan komunikasi telah membawa 
perubahan penting dalam perkembangan peradaban, terutama perekonomian dunia (Ristek, 2009). Hasil penelitian yang dilakukan oleh Qiang et. al. (2009) terhadap 120 negara pada rentang waktu tahun 1980-2006 telah memperlihatkan pengaruh yang positif antara peningkatan penetrasi berbagai layanan telekomunikasi (telepon tetap, telepon bergerak, internet dan fixed broadband) terhadap pertumbuhan perekonomian suatu negara, sebagaimana diperlihatkan dalam Gambar 7 di bawah ini.

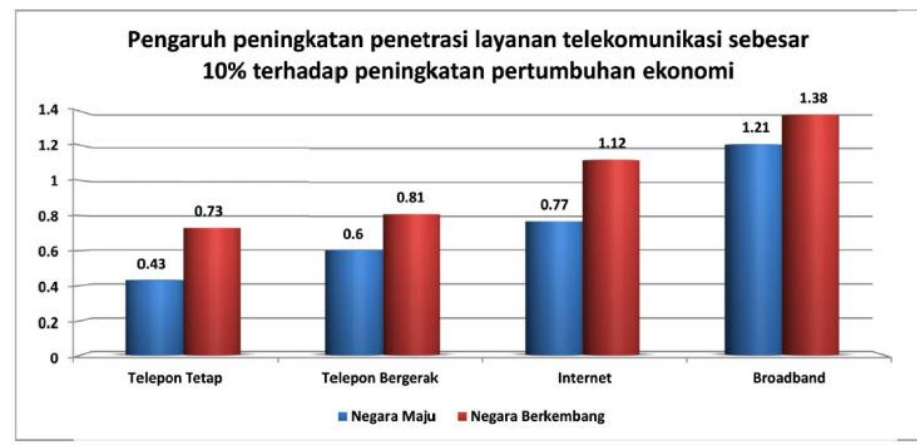

Gambar 7. Pengaruh Penetrasi Telekomunikasi terhadap Pertumbuhan Ekonomi

\subsection{Kondisi Inf rastruktur Eksisting}

Pembangunan sektor telekomunikasi di Indonesia secara umum masih belum memenuhi harapan. Hingga akhir tahun 2013, penetrasi layanan telekomunikasi per 100 penduduk (teledensitas) di Indonesia secara umum masih berada di bawah angka penetrasi rata-rata dunia, seperti diperlihatkan dalam Tabel 2 di bawah ini.

Tabel 2. Perbandingan Teledensitas Telekomunikasi Tahun 2013

\begin{tabular}{|l|c|c|c|c|c|}
\hline Teledensitas & $\begin{array}{c}\text { Telepon } \\
\text { Tetap }\end{array}$ & $\begin{array}{c}\text { Telepon } \\
\text { Bergerak }\end{array}$ & $\begin{array}{c}\text { Mobile } \\
\text { Broadband }\end{array}$ & $\begin{array}{c}\text { Fixed } \\
\text { Boadband }\end{array}$ & $\begin{array}{c}\text { Pengguna } \\
\text { Internet }\end{array}$ \\
\hline Negara Maju & $41.6 \%$ & $128.2 \%$ & $74.8 \%$ & $27 \%$ & $76,8 \%$ \\
\hline $\begin{array}{l}\text { Negara } \\
\text { Berkembang }\end{array}$ & $11.1 \%$ & $89.4 \%$ & $19.8 \%$ & $6 \%$ & $30,7 \%$ \\
\hline Dunia & $16.5 \%$ & $96.2 \%$ & $29.5 \%$ & $10 \%$ & $38,8 \%$ \\
\hline Indonesia & $1,22 \%$ & $115,2 \%$ & $12 \%$ & $1,22 \%$ & $15,36 \%$ \\
\hline
\end{tabular}

Sumber : ITU, 2013

Pada tingkat Asia Tenggara, teledensitas telekomunikasi di Indonesia secara umum juga masih berada di bawah negara-negara tetangga lainnya, seperti diperlihatkan dalam Tabel 3 di bawah ini.

Tabel 3. Teledensitas Telekomunikasi di Asia Tenggara Tahun 2012

\begin{tabular}{|l|c|c|c|c|}
\hline \multicolumn{1}{|c|}{ Negara } & $\begin{array}{c}\text { Telepon } \\
\text { Tetap }\end{array}$ & $\begin{array}{c}\text { Telepon } \\
\text { Bergerak }\end{array}$ & Internet & $\begin{array}{c}\text { Fixed } \\
\text { Boadband }\end{array}$ \\
\hline Singapore & $26,08 \%$ & $153,2 \%$ & $74,18 \%$ & $26,08 \%$ \\
\hline Malaysia & $8.39 \%$ & $140,94 \%$ & $65,8 \%$ & $8,39 \%$ \\
\hline Thailand & $6.23 \%$ & $120,29 \%$ & $26,5 \%$ & $6,23 \%$ \\
\hline Vietnam & $4,96 \%$ & $149,41 \%$ & $39,49 \%$ & $4,96 \%$ \\
\hline Brunei D. & $4,81 \%$ & $113,77 \%$ & $60,27 \%$ & $4,81 \%$ \\
\hline \hline
\end{tabular}




\begin{tabular}{|l|c|c|c|c|}
\hline Filipina & $2.23 \%$ & $106,77 \%$ & $36,24 \%$ & $2,23 \%$ \\
\hline Laos & $1,46 \%$ & $101,85 \%$ & $10,75 \%$ & $1,46 \%$ \\
\hline Indonesia & $1,22 \%$ & $115,2 \%$ & $15,36 \%$ & $1,22 \%$ \\
\hline Kamboja & $0,21 \%$ & $131,96 \%$ & $4,94 \%$ & $0,21 \%$ \\
\hline Myanmar & $0,01 \%$ & $11,16 \%$ & $1,07 \%$ & $0,01 \%$ \\
\hline
\end{tabular}

Sumber : ITU, 2013

\section{Analisa Pemilihan Teknologi}

\subsection{Asumsi Perbandingan Teknologi}

\subsubsection{Teknologi yang dibandingkan}

Dari hasil studi literatur yang dilakukan dan mempertimbangkan kesesuaiannya dengan kebutuhan operator telepon tetap di Indonesia, maka teknologi yang dibandingkan dalam penelitian ini adalah teknologi FWA yang berbasis teknologi selular, seperti diperlihatkan dalam Tabel 4. Sedangkan teknologi selular yang ada dan diimplementasikan di Indonesia diperlihatkan dalam Tabel 4.2. Dari Tabel 5 terlihat bahwa dari ketiga teknologi selular yang memungkinkan untuk diimplementasikan, GSM1800 dan CDMA2000-1X menjadi alternatif utama yang paling mungkin digunakan.

Tabel 4. Kesesuaian Kebutuhan Operator dengan Teknologi FWA

\begin{tabular}{|l|l|l|l|l|}
\hline \multicolumn{1}{c|}{$\begin{array}{c}\text { Kebutuhan Operator } \\
\text { Telepon Tetap di Indonesia }\end{array}$} & \multicolumn{1}{c|}{ Basis Teknologi FWA } \\
\cline { 2 - 5 } & \multicolumn{1}{c|}{ Selular } & \multicolumn{1}{c|}{ Proprietary } & \multicolumn{1}{c|}{ Mordless } & \multicolumn{1}{c|}{ Microwave } \\
\hline Dominan untuk layanan telepon & Memenuhi & Memenuhi & Memenuhi & Kurang memenuhi \\
\hline Kebutuhan Trafik Data yang mulai tumbuh & Sesuai & Sesuai & Sesuai & Kurang sesuai \\
\hline Ketersediaan Alokasi Frekuensi & Ada & Ada, terbatas & Ada, terbatas & Belum teralokasikan \\
\hline Tidak terpengaruh curah hujan yang tinggi & Relatif memenuhi & Kurang memenuhi & Kurang memenuhi & Tidak memenuhi \\
\hline Toleran terhadap halangan (terutama gedung) & Relatif memenuhi & Kurang memenuhi & Kurang memenuhi & Tidak memenuhi \\
\hline Jangkauan yang jauh & Memenuhi & Kurang memenuhi & Tidak memenuhi & Memenuhi \\
\hline Layanan tambahan seperti ponsel & Tersedia & Relatif tersedia & Kurang tersedia & Sangat terbatas \\
\hline Kapasitas Tinggi & Memenuhi & Memenuhi & Memenuhi & Memenuhi \\
\hline Biaya ekonomis & Memenuhi & Kurang memenuhi & Kurang memenuhi & Tidak memenuhi \\
\hline Luas digunakan & Sangat luas & Terbatas & Terbatas & Sangat terbatas \\
\hline Multi Vendor & Memenuhi & Tidak Memenuhi & Relatif Memenuhi & Tidak Memenuhi \\
\hline
\end{tabular}

Tabel 5. Teknologi Selular di Indonesia

\begin{tabular}{|c|c|c|c|c|c|c|}
\hline Teknologi Selular di Indonesia & GSM 900 & GSM1800 & IS-95B & CDMA2000-1X & AMPS & NMT450 \\
\hline Ketersediaan alokasi Frekuensi & Tidak Tersedia & Tersedia & Tersedia & Tersedia & Tidak tersedia & Tidak Tersedia \\
\hline Pengguna dan jumlah sst & \begin{tabular}{|l|} 
Telkomsel (5 Juta) \\
Satelindo (3 Juta) \\
Excelcomindo (2 Juta)
\end{tabular} & $\begin{array}{l}\text { INDOSAT-M3 (500.000) } \\
\text { Telkomsel (N/A) } \\
\text { Satelindo (N/A) } \\
\text { Excelcomindo (N/A) } \\
\text { Natrindo }(50.000)\end{array}$ & $\begin{array}{l}\text { Telkom Divre } 5 \\
(7.926)\end{array}$ & \begin{tabular}{|l|} 
Telkom (1,6 Juta) \\
Ratelindo (165.000)
\end{tabular} & $\begin{array}{l}\text { Komselindo }(40,653) \\
\text { Telesera }(9,900) \\
\text { Metrosel }(59,952)\end{array}$ & Mobisel $(7,543$ \\
\hline Kualitas Telepon & Baik & Baik & Baik & Baik & Kurang baik & Kurang baik \\
\hline Dukungan Highspeed & Kurang mendukung & Mendukung & Kurang mendukung & Mendukung & Mendukung & Mendukung \\
\hline Jangkauan Sel & Jauh & Relatif Jauh & Relatif Jauh & Jauh & Jauh & Sangat Jauh \\
\hline Kapasitas Sel & Tinggi & Tinggi & Sangat Tinggi & Sangat Tinggi & Rendah & Rendah \\
\hline
\end{tabular}

\subsubsection{Kriteria Penilaian}

Untuk menentukan kriteria penilaian sebagai pembanding kemampuan masingmasing teknologi, digunakan pertimbangan praktis dari operator telepon tetap serta rekomendasi ITU yang terkait dengan implementasi FWA menggunakan teknologi selular. Dalam memilih teknologi akses wireless, beberapa pertimbangan yang biasa digunakan oleh operator adalah : 
1. infrastruktur dapat dibangun secara cepat, berkapasitas besar, ekonomis, reliable dan berkualitas tinggi,

2. sederhana dalam instalasi dan pemeliharaan,

3. sistem yang flexible dan modular sehingga memudahkan untuk dikembangkan, baik jenis layanan maupun kapasitasnya,

4. performansi yang baik dalam mengatasi kondisi propagasi sehingga layanan dapat tetap berkualitas setara dengan wireline,

5. kemampuan untuk melayani area geografis yang luas,

6. kemampuan menyediakan layanan voice dan data serta kemampuan untuk ber-evolusi ke generasi selanjunya ,

Sedangkan ITU-R dalam Rec. F.1499 menyatakan bahwa sistem FWA berbasis teknologi selular yang dipilih harus memenuhi persyaratan teknis sebagai berikut :

1. mampu untuk mendukung layanan yang mendekati layanan wireline dan setara dengan kualitas selular,

2. memenuhi persyaratan performansi layanan suara (MOS setara atau lebih baik dari kualitas $32 \mathrm{bit} / \mathrm{s}$ ADPCM) dan layanan data yang mampu mensupport minimal 9600 bit/s hingga $64 \mathrm{kbps}$,

3. pelanggan harus dapat memiliki nomor pelanggan wireline,

4. pelanggan harus dapat melakukan kemampuan panggilan lokal seperti pelanggan telepon tetap PSTN,

5. memiliki manajemen terminal tetap yang remote,

6. mampu memberikan layanan telepon umum, modem dan fax,

7. memiliki kemampuan charging dan memonitor performansi,

8. memiliki catu daya dan proteksi petir, dan

9. memiliki display pada terminal pelanggan (optional).

Mempertimbangkan kebutuhan operator dan persyaratan ITU diatas, maka dalam penelitian ini, kriteria penilaian yang dipilih untuk mengevaluasi keunggulan dan kelemahan kedua teknologi FWA tersebut adalah :

1. Kriteria teknis, yaitu topologi jaringan, kualitas layanan (suara), kapasitas pelanggan, kebutuhan dan cakupan BTS, performansi radio, kemudahan perencanaan dan pengembangan, ketersediaan spektrum frekuensi, kemampuan multi layanan, akomodasi layanan masa depan, ketersediaan dan kompatibilitas terminal dan kemudahan migrasi 3G.

2. Kriteria ekonomis, meliputi biaya investasi perangkat, investasi per pelanggan dan pengaruh kepadatan trafik terhadap investasi.

3. Analisa kelayakan usaha, meliputi analisa terhadap indikator kelayakan usaha yaitu Net Present Value (NPV), Internal rate Return (IRR), Profitability Index (PI), dan Payback Period (PP).

4. Analisa sensitifitas terhadap jumlah pelanggan baru per tahun dan Average Revenue Per User (ARPU) minimum yang harus diperoleh agar rencana usaha layak diimplementasikan.

\subsection{Evaluasi Kriteria Teknis}

Untuk melakukan evaluasi kriteria teknis digunakan asumsi-asumsi sebagai berikut: 


\section{Asumsi umum :}

a. jumlah pelanggan $=200.000$ pelanggan,

b. rata-rata trafik per pelanggan $=100 \mathrm{mE}$ (urban),

c. distribusi pelanggan $=$ uniform (tersebar sama dan merata),

d. nilai grade of service $(\mathrm{GOS})=1 \%$ (standar ITU untuk layanan telepon tetap).

\section{Asumsi parameter BSS :}
a. sel BTS menggunakan tipe 3 sektor,
b. menggunakan 3 frekuensi carier per sektor,
c. total bandwith $=5 \mathrm{MHz}$,
d. CDMA carrier bandwith $=1,25 \mathrm{MHz}$,
e. kapasitas maksimal BSC : 512 BTS, 7500 Erlang (Class I)

\section{Asumsi parameter MSC :}

a. kapasitas maksimal MSC $=20.000$ Erlang (Class $\mathrm{I})$

Rangkuman dari penetapan kriteria dan hasil penilaian terhadap masing-masing alternatif teknologi FWA yang telah dilakukan, diperlihatkan dalam Tabel 6 . Secara keseluruhan, terlihat bahwa penyelenggaraan layanan telepon tetap menggunakan FWA CDMA2000-1X lebih unggul secara teknis dibanding FWA GSM1800.

Tabel 6. Hasil Evaluasi Kriteria Teknis

\begin{tabular}{|l|l|l|}
\hline Kriteria Evaluasi Teknis & \multicolumn{1}{|c|}{ FWA CDMA2000 } & \multicolumn{1}{c|}{ FWA GSM1800 } \\
\hline Topologi Jaringan & Fleksibel dan modular & Fleksibel dan modular \\
\hline Kualitas Suara & MOS $=4.1$ & MOS $=4.0$ \\
\hline Kapasitas Pelanggan & 1740 pelanggan & 1002 pelanggan \\
\hline Kebutuhan BTS & 115 BTS & 200 BTS \\
\hline Cakupan BTS & $65,05 \mathrm{~km} 2$ & $7,47 \mathrm{~km} 2$ \\
\hline Performansi Radio & - Rugi Propagasi Lebih kecil & - Rugi Propagasi lebih besar \\
\hline & - Lebih tahan terhadap multipath fading & - Lebih rentah terhadap multipath fading \\
\hline Perencanaan \& Pengembangan & Lebih mudah, bebas reuse frekuensi & Terbatas faktor reuse frekuensi yang digunakan \\
\hline Ketersediaan Alokasi Frekuensi & Lebih luas, dapat dikembangkan & Tersedia secara terbatas (10 MHz) \\
\hline Kemampuan Multi Layanan & Lebih mendukung & Mendukung \\
\hline Akomodasi Layanan Masa depan & Lebih mengakomodasi & Mengakomodasi \\
\hline Ketersediaan \& Kompatibilitas Terminal & Tersedia luas, full compability & Tersedia luas, tidak mendukung forward compability \\
\hline Kemudahan Migrasi 3G & Lebih mudah, alokasi frekuensi sama & Terbatas, memerlukan alokasi frekuensi baru \\
\hline \multicolumn{2}{|c|}{ Secara keseluruhan, FWA CDMA2000 memiliki keunggulan teknis dibanding dengan FWA GSM1800 } \\
\hline
\end{tabular}

\subsection{Evaluasi Kriteria Ekonomis}

Kriteria ekonomis yang dianalisa meliputi biaya investasi perangkat, investasi per pelanggan dan pengaruh kepadatan trafik pelanggan dengan menggunakan asumsi-asumsi sebagai berikut :

1. Perangkat yang dibutuhkan mengacu kepada asumsi teknis yang telah digunakan dalam perencanaan kapasitas,

2. Tidak termasuk biaya pengadaan atau sewa gedung MSC (asumsi gedung milik sendiri).

Pada evaluasi ekonomis ini digunakan 3 skenario penyelenggaraan, yaitu :

1. FWA CDMA2000-1X.

Pada skenario ini akan dibangun investasi baru berupa jaringan FWA berbasis CDMA2000-1X, 
2. FWA GSM1800.

Pada skenario ini akan dibangun investasi baru berupa jaringan FWA berbasis GSM seluruhnya,

3. Network Sharing GSM1800.

Pada skenario ini akan dibangun jaringan FWA menggunakan jaringan eksisting GSM1800 yang telah dimiliki oleh operator tertentu dengan asumsi membutuhkan investasi baru sebesar 50\% investasi GSM1800 eksisting.

Hasil evaluasi ekonomis secara keseluruhan dirangkum dalam Tabel 7. dari tabel tersebut, terlihat bahwa secara keseluruhan implementasi teknologi FWA menggunakan CDMA2000-1X lebih ekonomis dibandingkan dengan implementasi menggunakan GSM1800 dan Network Sharing GSM1800.

Tabel 7. Hasil Evaluasi Kriteria Ekonomis

\begin{tabular}{|c|c|c|c|}
\hline Kriteria Ekonomis & FWA CDMA2000 & FWA GSM1800 & Network Sharing GSM1800 \\
\hline \multicolumn{4}{|l|}{ Biaya Investasi Telepon (USD) } \\
\hline $100 \mathrm{mE}$ (Urban) & $48,815,526$ & $170,867,505$ & $85,433,753$ \\
\hline $80 \mathrm{mE}$ (Sub Urban) & $39,567,785$ & $126,483,919$ & $41,325,709$ \\
\hline $60 \mathrm{mE}$ (Rural) & $28,929,215$ & $82,651,418$ & $63,241,959$ \\
\hline \multicolumn{4}{|l|}{ Investasi/Pelanggan (USD) } \\
\hline $100 \mathrm{mE}$ (Urban) & 244 & 854 & 427 \\
\hline $80 \mathrm{mE}$ (Sub Urban) & 198 & 632 & 316 \\
\hline $60 \mathrm{mE}$ (Rural) & 145 & 413 & 207 \\
\hline \multicolumn{4}{|c|}{ Implementasi FWA menggunakan CDMA2000 lebih ekonomis dibandingkan GSM1800 } \\
\hline maupun Network Sharing G & & & \\
\hline
\end{tabular}

\subsection{Evaluasi Kelayakan Usaha}

Analisa kelayakan usaha dilakukan terhadap kedua jenis teknologi FWA dengan 3 skenario penyelenggaraan yaitu FWA CDMA2000-1X, FWA GSM1800 dan Network Sharing GSM1800. Indikator kelayakan usaha yang digunakan adalah Net Present Value (NPV), Internal Rate of Return (IRR), Profitability Index (PI) serta Payback Period (PBP).

Dalam kasus ini, penyelenggaraan layanan telepon tetap menggunakan teknologi FWA dilakukan oleh salah satu penyelenggara layanan telepon tetap di Indonesia, dengan asumsi dasar sebagai berikut :

1. Kurs 1 USD : Rp. 10.000

2. Pertumbuhan Pelanggan : $25.000 /$ tahun

3. Average Revenue Per User (ARPU) :
a. Telepon : 172.760 (Referensi : Telkom)
b. SMS : Rp. 34.5552 (30\% dari ARPU Telepon)
c. Internet : Rp. 60.270 (Referensi Telkom)
d. Biaya Pasang Baru : Rp 295.000
e. Biaya Abonemen : Rp. 34.200

4. Tipe Tarif : Residensial 1

5. Pajak Penghasilan $(\mathrm{PPH}): 30 \%$

6. Bunga Bank : $19 \%$ 
7. Tambahan Investasi/satuan sambungan :
a. FWA CDMA200 : Rp. (2.617.324)
b. FWA GSM1800 : Rp. (867.030.796)
c. FWA Network Sharing : Rp. (433.515.398)

8. Biaya Operasional : $40 \%$ dari Pendapatan Operasional

9. Peningkatan Biaya Operasional : $5 \%$ / tahun

10. Investasi dilakukan 1 tahun sebelum pengoperasian

11. Depresiasi dengan metode straigline dengan masa operasional perangkat 10 tahun

12. Pendanaan : 100 persen modal sendiri

13. Layanan : Telepon, SMS, Highspeed Internet

Hasil analisa kelayakan usaha untuk kondisi sewajarnya (base case) terhadap penyelenggaraan layanan telepon tetap menggunakan skenario penyelenggaraan CDMA2000-1X, GSM1800 dan Network Sharing GSM1800 diperlihatkan dalam Tabel 8 dibawah ini.

Tabel 8. Hasil Evaluasi Kelayakan Usaha

\begin{tabular}{|l|r|r|r|} 
Indikator & FWA CDMA2000 & FWA GSM1800 & Network Sharing GSM1800 \\
\hline Net Present Value (NPV) & $194,438,717,972$ & $(947,291,138,943)$ & $(129,582,960,571)$ \\
\hline internal Rate Return (IRR) & $26 \%$ & $3.24 \%$ & $15.55 \%$ \\
\hline Payback Period (PP) & 4 tahun 4 bulan & 7 tahun 1 bulan & 5 tahun 9 bulan \\
\hline Profitability index (P)) & 1.37 & 0.45 & 0.85 \\
\hline Kesimpulan & Layak & Tidak Layak & Tidak Layak \\
\hline
\end{tabular}

Dari Tabel 8 diatas, diperlihatkan bahwa penyelenggaraan layanan telepon tetap menggunakan teknologi FWA berbasis CDMA2000-1X layak untuk diimplementasikan. Sedangkan implementasi teknologi FWA berbasis GSM1800 maupun Network Sharing GSM1800 tidak layak untuk diimplementasikan karena tidak memenuhi kriteria kelayakan yang ditetapkan (NPV negatif, IRR $<19 \%$, PI $<1)$

\subsection{Analisa Sensitifitas}

Analisa sensitifitas dilakukan untuk menunjukkan pengaruh perubahan nilai beberapa faktor yang diasumsikan terhadap kelayakan usaha. Dalam kasus ini akan dilihat pengaruh peningkatan jumlah pelanggan serta pendapatan rata-rata yang diperoleh dari pelanggan tersebut (Average Revenue Per User/ARPU) dengan empat skenario bisnis, yaitu :

1. Base Case : merupakan skenario dasar, dengan asumsi terjadi peningkatan jumlah pelanggan sebesar 25.000 per tahun, ARPU Telepon sebesar Rp. 172.760 per bulan dan ARPU Internet Rp.60.270 per bulan.

2. Optimis : terjadi kenaikan jumlah pelanggan per tahun atau ARPU sebesar 10\% terhadap skenario Base Case.

3. Pesimis : terjadi penurunan jumlah pelanggan per tahun atau ARPU sebesar 10\% terhadap skenario Base Case.

4. Ambang : untuk mendapatkan besaran jumlah pelanggan pertahun atau ARPU masing-masing layanan agar dicapai kelayakan usaha (IRR = 19\%). 
Hasil analisa sensitifitas menggunakan 4 skenario bisnis tersebut dirangkum dalam Tabel 4.9 dibawah ini.

Tabel 4.9. Hasil Analisa Sensitifitas

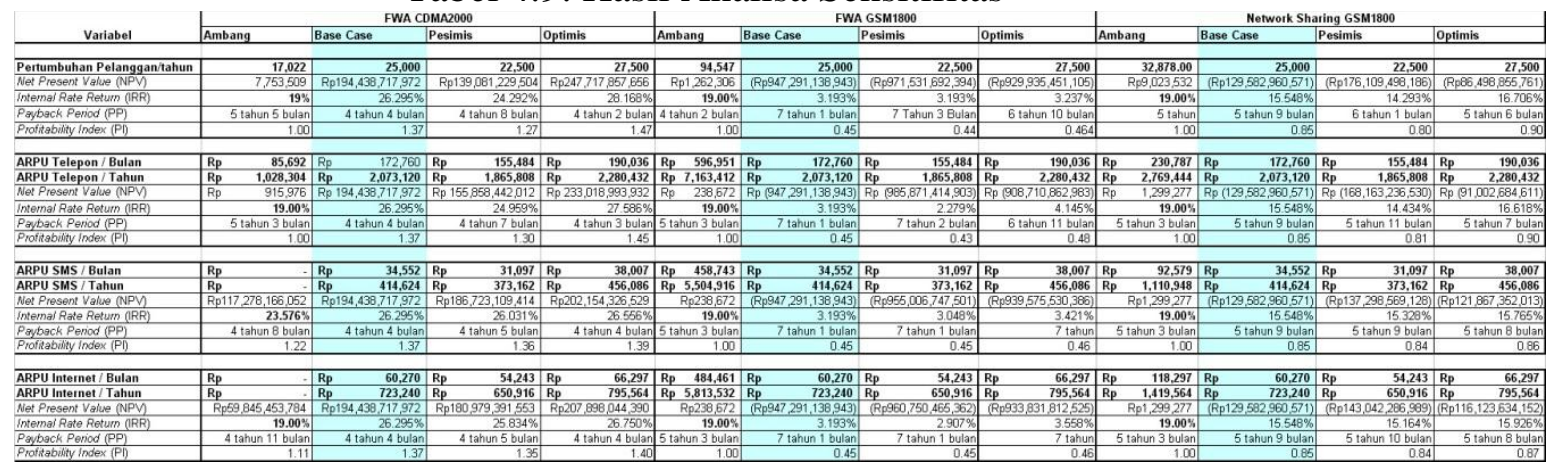

Dari hasil analisa sensitifitas tersebut diperlihatkan bahwa implementasi teknologi FWA menggunakan CDMA2000-1X layak diselenggarakan pada semua skenario bisnis (basecase, optimis, maupun pesimis). Sebaliknya, implementasi teknologi FWA menggunakan skenario penyelenggaraan GSM1800 dan Network Sharing GSM1800 tidak layak untuk diimplementasikan pada semua skenario bisnis tersebut.

Ambang batas kelayakan penyelenggaraan FWA menggunakan skenario penyelenggaraan CDMA2000-1X, dicapai apabila terdapat peningkatan jumlah pelanggan/tahun minimal sebesar 17.022 pelanggan, atau terdapat rata-rata pendapatan per pelanggan (ARPU) layanan Telepon minimal sebesar Rp. 85.692,-. Sedangkan ARPU SMS dan ARPU Internet relatif tidak berpengaruh terhadap kelayakan penyelenggaraan (walaupun ARPU sebesar Rp. 0, rencana usaha tetap layak diselenggarakan).

Sedangkan ambang batas kelayakan penyelenggaraan FWA menggunakan skenario penyelenggaraan GSM1800, dapat dicapai apabila terdapat peningkatan jumlah pelanggan/tahun minimal sebesar 94.547 pelanggan, atau terdapat ARPU Telepon minimal sebesar Rp. 596.951,-, atau ARPU SMS minimal sebesar Rp. 458.743,-, atau ARPU Internet minimal sebesar Rp. 484.461,-.

Adapun ambang batas kelayakan penyelenggaraan FWA menggunakan skenario penyelenggaraan Network Sharing GSM1800, dapat dicapai apabila terdapat peningkatan jumlah pelanggan/tahun minimal sebesar 32.878 pelanggan, atau ARPU Telepon minimal sebesar Rp. 230.787,--, atau ARPU SMS minimal sebesar Rp. 92.579,-, atau ARPU Internet minimal sebesar Rp. 118.297,-.

\section{Kesimpulan dan Saran}

\subsection{Kesimpulan}

Berdasarkan analisa yang dilakukan, dapat disimpulkan secara garis besar sebagai berikut : 
1. Teknologi FWA berbasis CDMA2000-1X lebih layak dipilih untuk penyelenggaraan layanan telepon tetap di Indonesia, karena berdasarkan analisa yang dilakukan, dapat mengungguli teknologi teknologi FWA berbasis GSM1800 pada 11 (sebelas) dari 12 (dua belas) kriteria teknis serta pada ketiga kriteria ekonomis.

2. Penyelenggaraan layanan telepon tetap di Indonesia menggunakan teknologi FWA CDMA2000-1X akan memberikan tingkat pengembalian investasi yang baik dibandingkan dengan GSM1800 dan Network Sharing GSM1800.

3. Penggunaan teknologi FWA CDMA2000-1X juga dapat memberikan batas ambang yang lebih rendah untuk tercapainya kelayakan usaha, dibandingkan dengan penyelenggaraan FWA berbasis GSM1800 ataupun Network Sharing GSM1800

4. Layanan telepon tetap menggunakan FWA CDMA2000-1X dapat menjadi alternatif utama pemenuhan kebutuhan akses layanan telepon tetap di Indonesia secara cepat dengan investasi per pelanggan yang relatif lebih murah sehingga sangat sesuai untuk operator baru yang ingin segera dapat bersaing dengan operator eksisting (incumbent operator).

\subsection{Saran}

Pembahasan penelitian ini baru mencakup pertimbangan untuk pemilihan teknologi FWA untuk penyelenggaraan layanan telepon tetap serta memberikan gambaran kelayakan usahanya di Indonesia.

Beberapa permasalahan yang perlu dikaji lebih lanjut, antara lain :

1. Kebijakan penyelenggaraan layanan telepon tetap.

a) Bagaimana mekanisme pentarifan untuk layanan telepon tetap menggunakan FWA berbasis selular yang mampu memberikan layanan full mobility, limited mobility dan no mobility?

b) Bagaimana pengaturan penomoran agar tetap dapat menggunakan alokasi penomoran telepon tetap yang selama ini digunakan PT.TELKOM ?

c) Apakah diperlukan pengaturan dan pembatasan layanan mobilitas agar tidak mematikan bisnis operator selular?

d) Bagaimana pengaturan interkoneksi antar operator telepon tetap, apakah sebaiknya memakai konsep Sender Keep All (SKA) atau pembagian revenue per panggilan?

e) Bagimana pula pengaturan interkoneksi layanan SMS melalui telepon tetap? apakah diijinkan interkoneksi langsung dengan sistem SMS melalui operator selular?

2. Efisiensi jaringan nasional terkait penyelenggaraan layanan telepon tetap menggunakan skenario Network Sharing (N/S).

a) Bagaimana pengaturan dan mekanisme yang yang tepat untuk melakukan skenario penyelenggaraan Network Sharing (N/S) dengan operator selular eksisting? 
b) Bagaimana pengaturan trafiknya agar penyelenggaraan layanan telepon tetap melalui Network Sharing (N/S) tidak mengganggu trafik eksisting operator selular?

c) Berapa besar sebenarnya penghematan yang dilakukan dibanding investasi baru dengan studi kasus pada operator selular?

\section{Daftar Pustaka}

[1] ITU, 1996. Handbook on Land Mobile (including Wireless Acces) : Wireless Access Local Loop, Volume I, Geneva: International Telecommunication Union.

[2] ITU, 2001. Handbook on Land Mobile (including Wireless Acces) : Fixed Wireless Access, Volume I, Geneva: International Telecommunication Union.

[3] ITU, 2013. World Telecommunication/ICT Indicators Database 2013. (17th Edition). Geneva: International Telecommunication Union.

[4] ITU,1999. Manual on Mobile Communication Development, BDT, 1999.

[5] ITU, 2013. World Telecommunication Development Report.

[6] Ristek, R.,2009. Penelitian, Pengembangan dan Penerapan Ilmu Pengetahuan dan Teknologi Bidang Teknologi Informasi dan Komunikasi. Working Paper.

[7] Qiang, Christine Zhen-Wei, and Carlo M. Rossotto, 2009. Economic Impacts of Broadband. In Information and Communications for Development 2009: Extending Reach and Increasing Impact, World Bank, WDC: 35-50

[8] Webb, W., Introduction to Wireless Local Loop, Artech House, 1998. 